\title{
How Can Responsible Family Ownership be Sustained Across Generations? A Family Social Capital Approach
}

\author{
Cristina Aragón-Amonarriz ${ }^{1}$ Agustín Mateo Arredondo ${ }^{2}$. \\ Cristina Iturrioz-Landart ${ }^{1}$
}

Received: 13 July 2016 / Accepted: 31 October 2017 / Published online: 8 November 2017

(c) The Author(s) 2017. This article is an open access publication

\begin{abstract}
Responsible family ownership (RFO) is a combination of the family's commitment to the family-firm's (FF's) stakeholders in the long term and the explicit behaviour of the family members associated with the firm. However, families are not individuals but rather a system of relationships among family members. In such a context, misunderstandings in communication, anachronistic mentalities and different value systems can block the intergenerational transmission of RFO. Consequently, the responsibility of the family towards the FF's stakeholders may be damaged and the firm's socially responsible behaviour hindered. This paper aims to identify how RFO is transferred across generations and to ascertain the role that family social capital (FSC) plays in preserving the transmission of RFO from generation to generation. Our research is based on three in-depth case studies of Mexican family-owned small- and medium-sized enterprises. First, the paper identifies and contrasts a set of FSC-specific factors and problems which play a relevant role in the transmission of RFO while recognizing the influence of the mutually reinforcing dynamics of FSC dimensions. Secondly, the family's honourableness (Aßländer in J Bus Ethics 116(4):751-767, 2013) is identified as a key driver for sustaining the transmission of RFO.
\end{abstract}

Cristina Aragón-Amonarriz

cristina.aragon@deusto.es

Agustín Mateo Arredondo

agustin.mateo@itesm.mx

Cristina Iturrioz-Landart

cristina.iturrioz@deusto.es

1 Deusto Business School, University of Deusto (Spain), Mundaiz, 50, 20012 San Sebastián, Spain

2 Instituto Tecnológico de Monterrey, Av. Eugenio Garza Sada 1500, s/c, 20328 Aguascalientes, AGS, Mexico
Finally, the paper identifies RFO institutionalization required to face the intrinsic problems of transmitting RFO in growing families.

Keywords Responsible ownership · Social capital · Family SMEs · Case study · Intergenerational transmission

\section{Introduction}

Corporate social responsibility, which is broadly defined as the extent to which firms voluntarily integrate social and environmental concerns into their ongoing operations and interactions with stakeholders, is becoming a mainstream issue as both researchers and managers realize its importance (Godos-Diez et al. 2011). In the context of SMEs, the owners' values are considered a main source of social responsibility (SR) (Aragón et al. 2015; Lepoutre and Heene 2006; Preuss and Perschke 2010). This source is even more relevant in the case of family SMEs, where the overlapping relationships that exist between the family and the firm are at the root of their SR and of their firm's competitiveness (Habbershon and Williams 1999).

In this sense, responsible ownership implies the development of a specific responsibility within the family owning the firm, i.e. a combination of "an active and long-term commitment to the family, the business and the community, and balancing these commitments with each other" (Lambrecht and Uhlaner 2005, p. 8) and the behaviours associated with it (Berent-Braun and Uhlaner 2012). Taking into account the specificities of family SMEs, Aragon and Iturrioz (2014) developed and adapted the construct for SMEs, which they termed responsible family ownership, or RFO. According to these authors, RFO is a combination of the family's commitment to and their derived behaviour towards 
the family-firm's (FF's) stakeholders in the long term. Responsible FFs share a sense of belonging with stakeholders, employees, customers and suppliers (Deniz and Cabrera 2005). In addition, they are embedded in their local communities and thus become more engaged with their environment (Sharma and Sharma 2011; Uhlaner et al. 2012).

Family networks usually include not only relationships among family members of the same generation, but also hierarchical and asymmetric relationships among members of different generations (Wade-Benzoni 2002) where misunderstandings in communication, anachronistic mentalities and different value systems are factors which challenge the sustainability of RFO over time. The intergenerational transmission of RFO is therefore crucial to preserve the family owners' responsibility towards the firm and the community in that it affects not only a firm's socially responsible behaviour but also possibly its continuity. Consequently, the question is: How can RFO be preserved and transferred across the family's generations?

The FF's salient group, the family, is a system of people who share common values, relationships and purpose, and whose members are embedded in their FSC (Arregle et al. 2007). Following Bubolz (2001, p. 130), "family is a source, builder and user of social capital", and Coleman (1988), who considers the relationships among family members to be an ideal environment to develop social capital (SC), we consider that families may provide the foundation of moral behaviour on which guidelines for cooperation and coordination, as well as principles of reciprocity and exchange, are developed (Bubolz 2001). Increased reciprocity and exchange reinforce the creation and use of SC which arises from the dynamic factors of stability, interdependence, interactions and closure which are common in FFs. Therefore, we contend that FSC plays a relevant role in building and transferring RFO across generations. In this paper, we aim to identify how RFO is transferred and to ascertain the role that FSC plays in transmitting RFO across generations, as well as the problems and dynamics families must face to do so.

To understand what role FSC plays in the transfer of RFO, we follow a qualitative methodology to explain a particularly complex phenomenon that involves the identification of values, relationships and behaviours of different generations of family members over time. Specifically, three in-depth case studies of Mexican family-owned SMEs are analysed. It is noteworthy that one of the most important cultural characteristics in Mexico is the family and that the three selected cases demonstrate RFO together with a high level of SR.

The main contributions of our research are the following. First, the study brings to light the complexity of transmitting RFO and provides a theoretical framework on how RFO is transferred across generations, thus contributing to the literature on responsible ownership. The development of this literature is the first step in identifying how the main stakeholders in FFs influence their SR, as suggested in the research agenda for SR in SMEs (Spence 2007). In particular, when examining the role of FSC from a holistic perspective, we have observed honourableness as a family precondition and driver of RFO transfer and the need for institutionalization of this RFO as the family grows. Second, in addition to its academic value, this paper illustrates the problems and dynamics which can be applied practically to the governance of family SMEs and which can provide insights into the heterogeneous SR of FFs (Deniz and Cabrera 2005).

In the following sections, we first present a review of the literature on responsible ownership. We go on to develop the FSC concept and (based on the SC approach) detail the key FSC factors which play a relevant role in the transfer and sustainability of RFO, identifying the positive influence of these factors as well as their negative effects on the process of transferring RFO. We then present the methodology and the three case studies, before finally discussing the implications of our findings.

\section{Responsible Family Ownership and Family SMEs}

Chua et al. (1999, p. 25) provide the following definition of FFs: "a business governed and/or managed with the intention to shape and pursue the vision of the business held by a dominant coalition controlled by members of the same family or a small number of families in a manner that is potentially sustainable across generations of the family or families". Using this definition, many scholars maintain that the uniqueness of FFs arises from the integration of family and business (Habbershon and Williams 1999; Sirmon and Hitt 2003). This integration has different manifestations: the dual roles of people as members of the family and members of the firm, the integral role of the business for the family's biography and the inability of the family to leave the firm entirely (Distelberg and Sorenson 2009; Dyer and Whetten 2006). This specific nature creates a context in which, "due to their ownership, family members enjoy certain control rights over the firm's assets and use these rights to exert influence over decision-making processes in an organisation" (Carney 2005, p. 251). In particular, several authors (such as Berrone et al. 2010; Dyer and Whetten 2006; Sharma and Sharma 2011) suggest that FFs are significantly different from other types of organizations when it comes to social issues.

In this sense, family involvement has been considered an antecedent of SR in FFs (Bingham et al. 2011; O'Boyle et al. 2010). The effects of the family's involvement on SR engagement can be understood in the same way as Marques et al. (2014, p. 218) state in their work on stewardship theory, "family involvement creates better psychological and situational factors to promote a pro-CSR stewardship 
behaviour". Another explanation, based on the socioemotional wealth (SEW) approach, is also possible. Following this rationale, greater family involvement leads to engaging stakeholder management as a way to enhance and protect socioemotional endowments (Cennamo et al. 2012) and avoids negligence, thus fulfilling the demands of stakeholders (Marques et al. 2014).

However, there is no consensus on this topic. Some authors (such as Dyer and Whetten 2006) found no significant differences between family and non-FFs regarding positive social initiatives. The literature also includes cases where FFs have ignored and even abused non-family stakeholders (Gallo 2004; Kidwell and Kidwell 2010). This ambiguity is also present when considering the dimensions of SEW. In this sense, Kellermanns et al. (2012) note that they could be both positively and negatively valenced in terms of proactive stakeholder engagement. Thus, following Cruz et al. (2014, p. 1310), SEW can be a "double-edged sword", eliciting both socially responsible and socially irresponsible behaviour in FFs and having both a positive and a negative side. Thus, the SEW perspective can explain why FFs are often seen as caring for their stakeholders (Berrone et al. 2012; Dyer and Whetten 2006) and why some FFs seem to have little regard for stakeholders, particularly non-family stakeholders. This perspective helps to explore why some firms care more about the needs of stakeholders than others do (Cennamo et al. 2009).

A positive or negative valence of SEW can lead to a higher or lower level of SR in FFs in comparison with nonFFs, and it can also influence SR with respect to the type of stakeholder (Cruz et al. 2014; Gallo 2004). In fact, Cruz et al. (2014) prove that, due to their concern with image and reputation as a way to protect their SEW, FFs are likely to be more responsive to external stakeholder demands than non-FFs. In contrast, their concern with control and influence within the company and their strong emotional attachment to it (two other crucial SEW dimensions) are likely to determine social actions related to internal stakeholders.

In this paper, we do not focus on the quantitative difference in SR between family and non-FFs. Instead, we focus solely on socially responsible FFs and, in particular, family SMEs, which require the development of a specific responsibility within the family owning the firm. The osmotic relationship between family and firm is further intensified in family SMEs (Niehm et al. 2008) where, due to the overlap between ownership and management, family members can directly influence the firm's social behaviour, among other things. Following and adapting the concept of responsible ownership to family SMEs in the existing literature (Aronoff and Ward 2001; Berent-Braun and Uhlaner 2012; Lambrecht and Uhlaner 2005; among others), Aragon and Iturrioz (2014) went one step further and offered a new construct: responsible family ownership (RFO).
RFO is defined as the combination of "an active and longterm commitment to the family, the business and the community, and balancing these commitments with each other" (Lambrecht and Uhlaner 2005, p. 8), and the behaviours associated with this commitment (Berent-Braun and Uhlaner 2012). RFO contributes to the existing literature because it fits the requirements derived from the idiosyncratic nature of family SMEs. First, the familial nature, which allows for asymmetric power of a particular stakeholder, i.e. the family, influences the firm even if its members do not formally belong to the firm (Mitchell et al. 2011); second, the dimension of the firm that impacts on SR in FFs (Uhlaner et al. 2004) is usually associated with lack of or scarce governance mechanisms (Mustakallio et al. 2002). Such governance mechanisms avoid opportunistic behaviour in case of irresponsible ownership and demand explicit behaviour to evidence the commitment of the family to the stakeholders, due to the lack of formal statements (Adams et al. 1996).

However, in FFs, RFO is not a static achievement in that it requires the owner family to behave and remain responsible towards the stakeholders and the firm (Aragon and Iturrioz 2014). The RFO developed in one generation is at stake in the transgenerational succession. In this sense, one question remains unanswered: How can RFO be developed and preserved through time? In our paper, we attempt to understand the dynamics behind the intergenerational preservation of the owner family's responsiveness.

\section{The Role of Family Social Capital in the Transfer of Responsible Family Ownership}

FSC is transferred between the members of different generations thanks to emotional ties, behavioural principles and other rules (Wright et al. 2001). Based on the existence of RFO, the relational proximity and the intergenerational trust of the owner family allow the sustainable transfer of RFO across generations (Salvato and Melin 2008). Therefore, based on Nahapiet and Ghoshal (1998) and Arregle et al. (2007), the three dimensions of FSC (cognitive, structural and relational) have been applied to the RFO intergenerational transfer issue. (1) The cognitive dimension refers to the shared beliefs of the agents involved (Nahapiet and Ghoshal 1998); to the common needs, goals and agendas; and to the willingness and the ability of actors to identify and share collective, intergenerational, compatible interests and objectives. (2) The structural dimension focuses on the norms that facilitate relationships between members of different generations and the overall pattern of connections between them. (3) The relational dimension refers to the existence of a set of mutually held intergenerational values.

The family owners of firms have been associated with both positive and negative relationships with stakeholders, 
as noted by Deniz and Cabrera (2005). These authors conclude that a FF is not a homogeneous group in terms of SR. Following Moran and Ghoshal (1996), we contend that FSC can both facilitate the conditions for RFO transmission and hinder it. The lack of common vision and shared purposes among family members and other stakeholders (cognitive dimension), unbalanced relationships among family members (structural dimension) and/or an inflexible set of family values (relational dimension) could damage RFO sustainability in FFs. In this sense, we contend that dynamics to preserve the dimensions of FSC have to be developed and, in this case, FSC will provide the required support for the transfer of RFO. But, how will these FSC dimensions nurture this transfer?

First, and regarding the FSC cognitive dimension, unity throughout the firm and among its stakeholders is required. In the contrary case, miscellaneous interest can arise and the different generations of the family who are involved in the firm can engage in opportunistic behaviour. For instance, successors seeking quick and high performance could reduce certain key investments, thus damaging the firm's competitiveness. Interest involving different time horizons in each generation can also be at the root of these divergences. For instance, endless succession processes can lead to good candidates from the new generation becoming frustrated and eventually developing their professional careers outside of the FF. In this context, where senior generations have little or no probability of benefiting from responsible behaviour in the future, mutual reciprocity based on long-term common interests is challenged (Wade-Benzoni 2002).

In order to transfer RFO, the cognitive dimension of FSC has to be preserved. The requirements for unifying the family around the firm and its stakeholders are to balance business and social objectives as well as to consider the objectives from a long-term perspective. There is evidence that opportunistic behaviour, while highly profitable in the short term, can damage long-term competitiveness. Therefore, it seems necessary that family consensus is reached on a set of long-term objectives which balance social and business purposes. This consensus may sustain RFO across generations. For instance, FFs that preserve long-term engagement activities with society or avoid layoffs in crisis periods (Block 2010) show successful RFO transfer over time.

Second, regarding the transfer of RFO and the structural dimension of FSC, it is important to underline that owner-manager overlap is often extensive or even complete in family SMEs. Based on asymmetric information, the family (through an individual or a group) frequently governs the firm directly without any other formal mechanism (Mustakallio et al. 2002). As FFs grow older, the complexity of the family network structure increases. In this context, maintaining the governing modus operandi can undermine the possibility of spontaneous relations among family members.
Consequently, there are dysfunctional power arrangements within the firm (Leana and Van Buren 1999), such as the marginalization of part of the new generation in the FF's governance, in particular the siblings not working in the firm, which can decrease unity in the family and the firm (Salvato and Melin 2008). The FSC structural dimension, therefore, requires a balanced investment of internal SC (bonding) which is grounded in intragenerational family relationships as well as external SC (bridging) which focuses on ties among intergenerational family members or between family members and other stakeholders (Salvato and Melin 2008), considering the new generation as a new stakeholder. The FF's governance, which is centralized and informal at the beginning (Cabrera and Santana-Martín 2004), faces an increasing number of family members in the successive generations with limited contact with each other. This means that ties have to be established between members of the successor generation and between the predecessor and successor generations. In the contrary case, the professional development of the successor generation outside the FF along with minimal exposure to the firm's business and its stakeholders can reduce RFO. Additionally, RFO assumes the FF acts as a social agent that interacts responsibly with stakeholders, sharing their objectives and caring for them. In this sense, bridging the SC between family members and external stakeholders across generations allows for the nurturing of this family vision over time. Without the contact of different generations with stakeholders and their needs and interests, RFO can become an empty and old-fashioned tradition of previous generations.

Third, and regarding the FSC relational dimension, family values are of strategic importance in FFs (Tapies and Fernández Moya 2012), and their legacy is one of the most powerful ways to ensure the continued presence of the family in the firm (Aronoff and Ward 2001). The existing reputational costs are a disincentive for family members to behave in an opportunistic way, based on controversial values regarding the family's values, which are easily traceable by the community in which the FF is established. In familyowned SMEs, the family transfers their values from parents to children based on direct contact (Tapies and Fernández Moya 2012). If value systems are not supported by coherent behaviour, then the values cannot function as the basis for strengthening the relational SC dimension. New value systems adopted by new generations can try to integrate the pre-existing value systems. On the one hand, blocking the renewal of a value system can undermine the new generation's attraction to the firm, avoiding the healthy updating of the family membership in the firm and of its value system. On the other hand, a value system that accepts divergent values usually generates conflict, which results in the hindering of FSC (Arregle et al. 2007). To be able to transfer RFO, the FSC relational dimension requires a set of core values 
and a permanent focus on building a value system through consistent behaviour over time and involving members of both the predecessor and successor generations. However, making the value system rigid and inflexible is not the solution. Openness in peripheral issues and core stable values should be embraced by family members of both generations. The values of the successor generation will be influenced by those of the predecessor generation or by an alternative model of reference. In general, if these models are generous, future generations will be less self-interested and will respond to the spirit of generosity (Wade-Benzoni 2002).

Therefore, FSC seems to be the backbone of RFO transfer across generations. Given that our aim is to identify how to preserve RFO across generations, Table 1 illustrates the role that FSC dimensions play in transmitting RFO by identifying the key FSC factors for the transmission and sustainability of RFO, as well as their positive and negative influences in this transmission process.

\section{Research Methodology}

To be able to analyse the role of FSC in RFO transfer, we chose a qualitative methodology to collect the required information. The analysis of a subjective reality comprising multiple realities is allowed by the constructivist paradigm of the qualitative approach (Hernández-Sampieri et al. 2006). In our case, the phenomenon is particularly complex because it involves members of different generations over time, requiring a particular understanding of the viewpoint of these different generations by the researchers. This kind of research, including multiple and heterogeneous dimensions, requires collecting detailed experiences and obtaining in-depth information with d interpretive wealth (Eisenhardt 1989; Yin 1989). The aim of this study implies that each family develops RFO behaviour according to their own interpretation and circumstances. In this context, the case study approach is considered appropriate because it allows for analysis in context, simultaneously using different sources of evidence without losing the complexity and specificity of each case (Zikmund 2003).

Following Aragon and Iturrioz (2014), we have captured the RFO construct by considering both the long-term commitment of the family to their stakeholders and their explicit behaviour associated with responsible ownership, i.e. the professionalism of human resource management and the selection of leaders for management or ownership roles; the professionalism required for organizational and financial practices; and the appropriate means of planning for firm succession and long-term family vision.

A set of requirements were defined to identify the family-owned SMEs participating in the study: first, FFs which are at least in their second generation; second, FFs where members of different generations co-exist actively in the firm; and finally, FFs which are highly recognized for their socially responsible behaviour. Diverse primary and secondary sources, such as press releases in local newspapers and media ${ }^{1}$, internal documents and web pages (Table 2), together with the experience and knowledge of one of the co-authors about the firms, helped to verify the previous criteria. Additionally, to ensure access to the sensitive information required for the research project, professional contacts and again the experience of one of the co-authors of the paper were essential in selecting the final three case studies.

Once the cases were identified as appropriate for the study and the families agreed to participate, most of the data referring to the dimensions of RFO were extracted from indepth face-to-face interviews (Table 5).

In this study, we analyse three Mexican SMEs. SMEs are relevant to the Mexican economy because they represent $50 \%$ of this country's gross domestic product (GDP) and $70 \%$ of the employment opportunities for Mexican workers (Reyes and Preiss 2015). The majority of small- and medium-sized enterprises in Mexico are family-owned (Erdener 2009), and in fact, up to 95\% of all Mexican businesses are owned and managed by families. According to the national census (INEGI 2009), the distribution of FFs in the different sectors is approximately as follows: $50 \%$ commerce, $37 \%$ services and $13 \%$ manufacturing. The dominant economic pattern in Mexico is that each major industry is under the control of a leading family (Erdener 2009). However, very few studies refer to Mexican family businesses, mainly due to the difficulty in accessing information about company ownership and company control structure (Espinoza and Espinoza 2012).

The family is one of the most important cultural characteristics in Mexico. According to Belausteguigoitia (2007), families grow faster in Mexico than businesses do. Consequently, the number of family members looking for a position in the firm increases after the second generation. Additionally, the survival rate of FFs in Mexico is low. Following Betancourt et al. (2012), 70\% of FFs disappear after the death of the owner, and only about $10-15 \%$ survive to the third generation, which generally dissolves the company.

The ownership structure and corporate governance mechanisms in Mexico, as in other Latin American countries, differ from those in Anglo Saxon nations, as noted by Watkins-Fassler et al. (2017). Additionally, social cohesion is particularly robust in Latin American countries (Mizruchi 1996) and members of owning families interrelate among themselves as part of the same social network. In this sense, they are likely to strengthen the presence of family members

\footnotetext{
${ }^{1}$ El Norte Digital, El diario de Juarez, NTR Zacatecas and Imagen
} Zatatecas. 


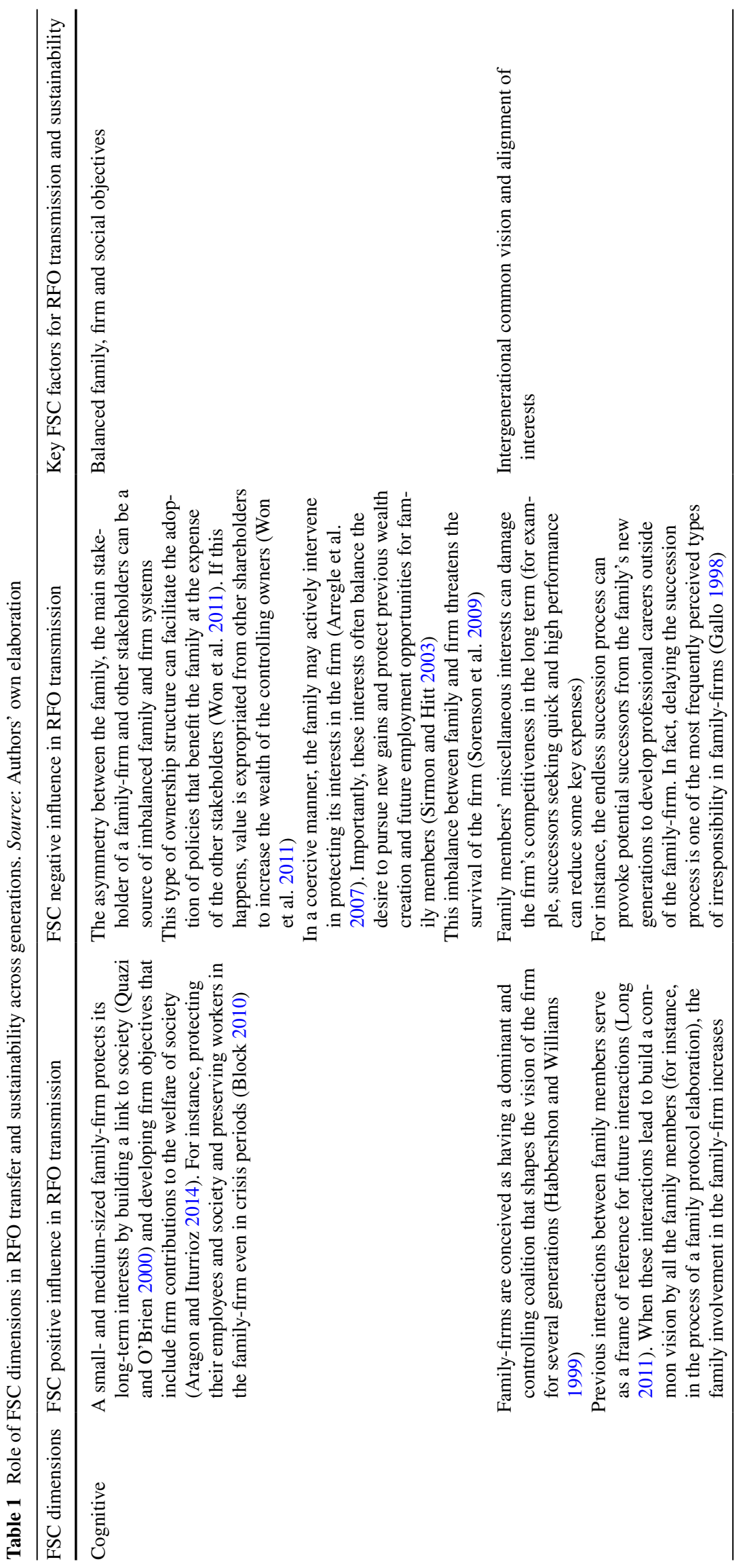




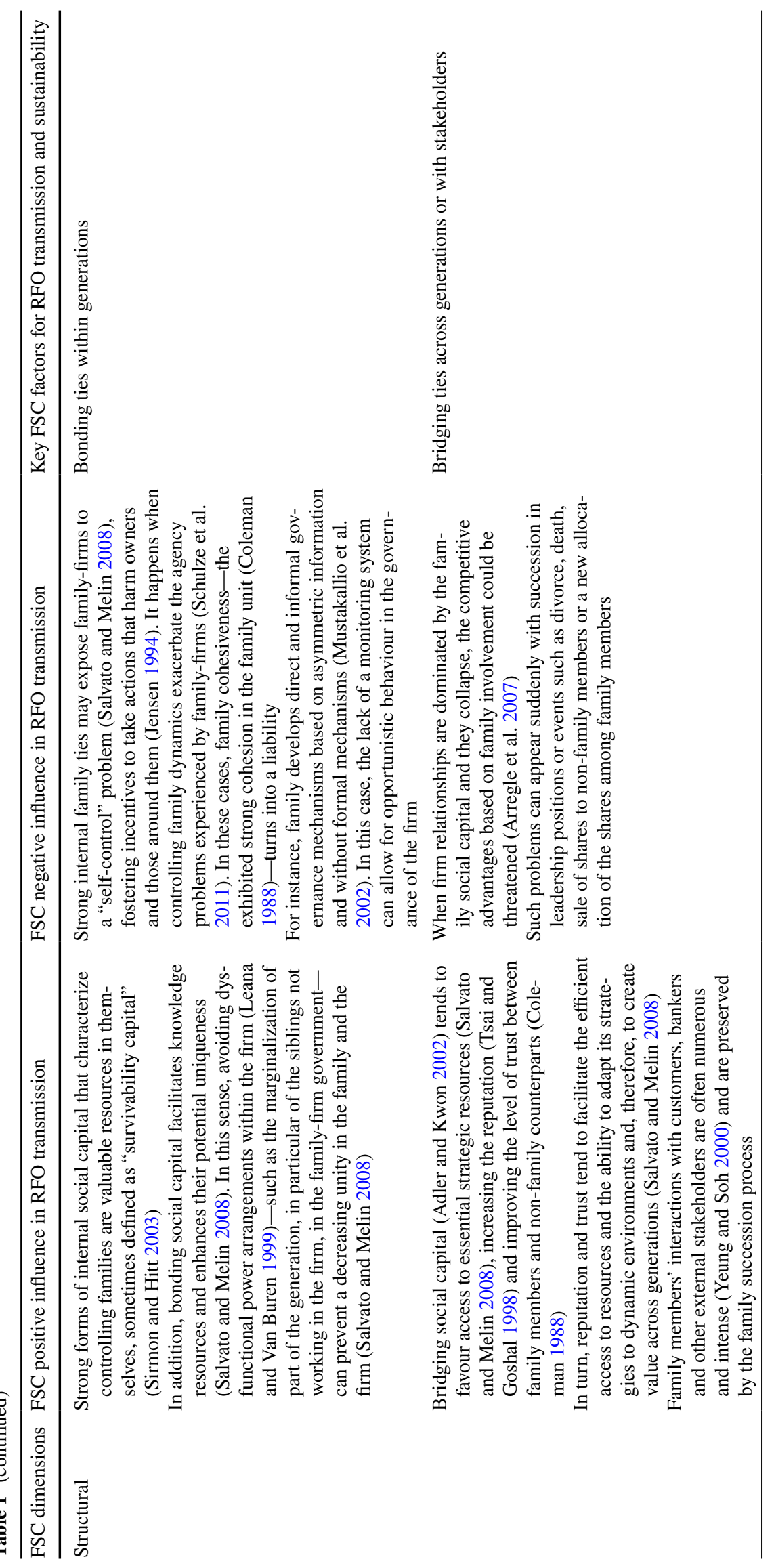




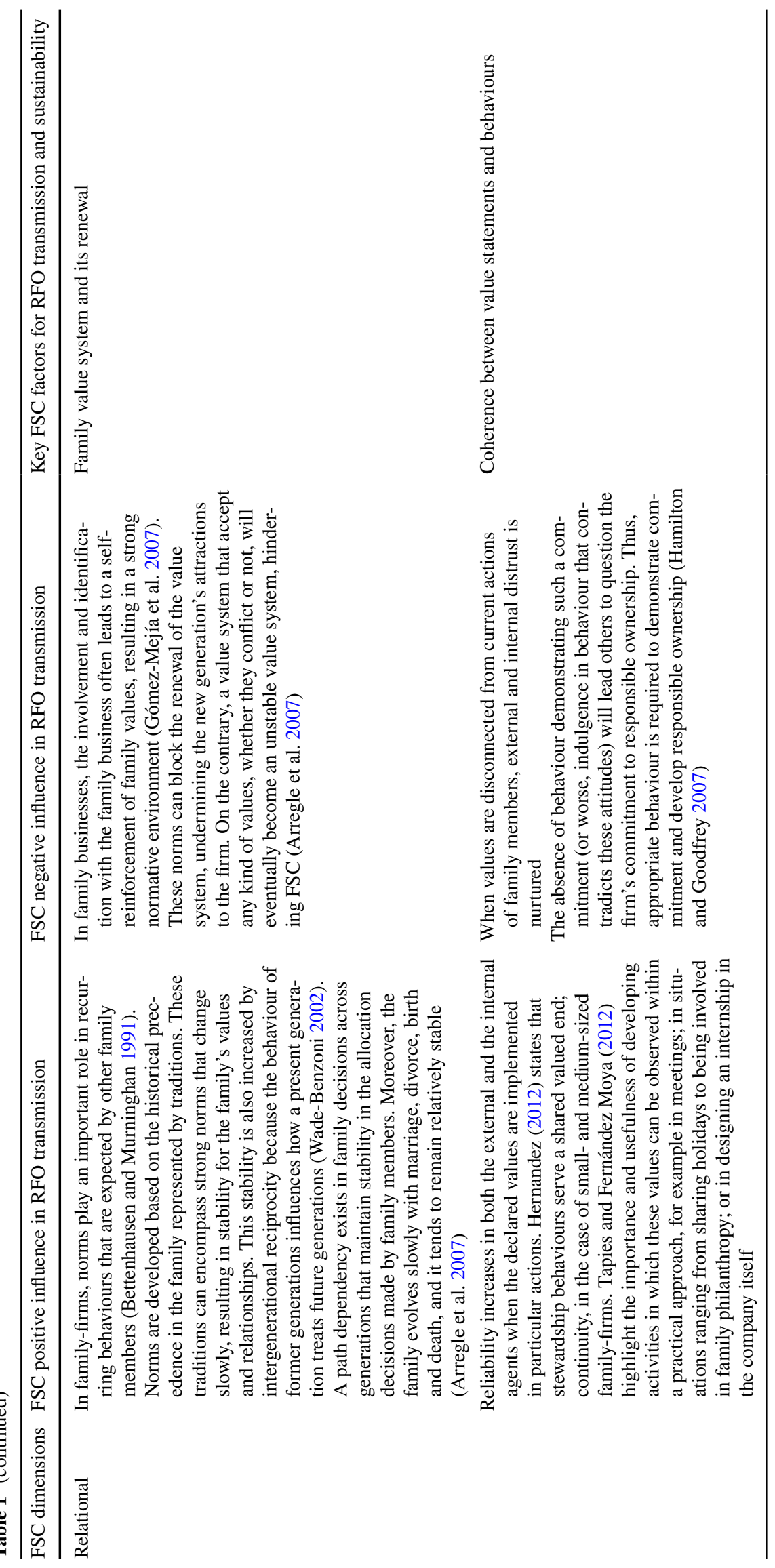




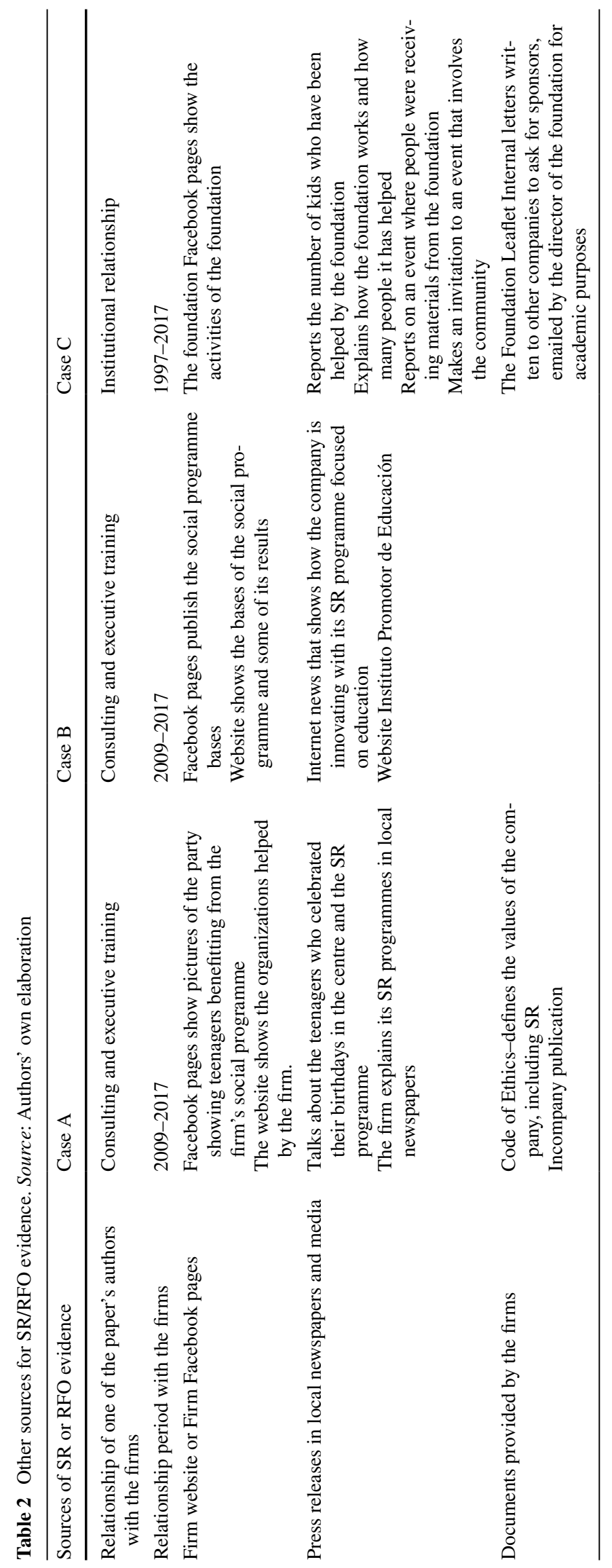


in relevant positions in FFs (board chairs and CEOs) and to build powerful business groups that facilitate interlocking directorate practices (Cárdenas 2014). Both characteristics make Mexican family SMEs a suitable context for observing the family operative in terms of RFO and FSC.

Considering the difficulty, which is intrinsic to Mexican FFs, of accessing information on ownership and control structures (Espinoza and Espinoza 2012), the selection of the families for this study was guided by the possibility of illustrating FSC dynamics with regard to the transmission of RFO across generations. We selected three Mexican families who owned family SMEs (defined here as an organization with fewer than 100 employees, following INEGI 2004) and who showed evidence of being responsible family owners, based on the knowledge that one of the authors had concerning the families in question. The evidence of responsible FFs was also extracted from external data such as web pages, newspapers and media. These external data served to verify that the FFs were recognized in their community for being responsible. In particular, we had access to documents such as codes of ethics and mission statements as well as online news in which the FFs were acknowledged because of their socially responsible programmes. We focused our study on the dynamics within the contexts of the three selected SMEs so as to illustrate the process of sustaining RFO across generations, despite the fact that two out of the three selected families have invested in or developed other firms. Two of the firms are involved in retailing and the third in services. Two of the firms are in the third generation, while one is in the second. The firms selected for our study are acknowledged by their socially responsible behaviour.

The primary characteristics of each SME, its family and its SR activities are listed in Table 3.

The style of our research has been to record our observations while remaining open and not losing perspective. We have used the same terms the interviewees used for the different governance structures. We conducted semi-structured interviews on the paper's key topics regarding FSC and RFO from August to October 2014. Our main source of data gathering (Table 5) was the interviews during which we made direct observations. We followed a thematic data analysis (Table 1) to organize the data set, thereby applying a deductive approach.

To be able to ensure access to the sensitive information required for the research project, we considered information from professional contacts, particularly in the selection of the families. We employed a holistic perspective, considering diverse criteria when identifying the profiles to interview: different generations, diverse levels of involvement in the firm, family members and non-family members. Following these criteria, there were at least four informants in each case: the top manager of the firm, a member of the family's predecessor generation, a member of the family's successor generation still working in the firm, a member of the family's predecessor generation not working in the firm and a non-family member working in the firm. In one of the cases, we followed the suggestion made by the firm's general manager to interview a fifth person. However, we found that redundant information was provided during this fifth interview, and we did not include a fifth informant in the second and third cases. We conducted a total of 13 interviews, lasting from 60 to $150 \mathrm{~min}$. The output of the interviews was recorded, transcribed (sometimes during the interview) and codified. The results of the transcription were then shared with the interviewees so as to correct any misinterpretations (Table 4).

To guarantee reliability, we followed several recommendations laid out by Yin (2003). First, we defined the generic purpose of the case to establish a formal protocol for the case study, and we then set up the procedure for gathering the data and compiled an interview guide (Table 5). A database containing all the empirical evidence was created following a thematic data analysis (Table 1) to be able to collect all the data and documents required to compile the final case study report. In particular, we made use of the experience of one of the co-authors who have collaborated for at least 8 years with the three cases.

The validity of the construct was guaranteed through the use and triangulation of various sources of evidence and by contrasting the data provided by the informants from each case (Yin 2003). The chain of evidence was constructed from several sources of information, gathering data which ensured triangulation (Eisenhardt 1989; Yin 1989). All these points of reference ensure that the issue is observed through a variety of lenses, which allows for multiple facets of the phenomenon to be revealed and understood (Baxter and Jack 2008).

Internal validity was guaranteed by the design of a dedicated framework, based on the relevant literature and preliminary assumptions. We searched for pattern matching and explanation building, and external validity was confirmed. Our case study research involved analytical generalization, in which particular findings are generalized into a broader theory (Yin 2003).

\section{Findings}

\section{Case Descriptions: The Family and the Firm}

Case A is a services firm, specifically, a convention and social events centre which was set up in 1991 by three families. Firm equity is shared equally by the three families, and each family branch has a member of the first generation and another of the second generation participating in the 


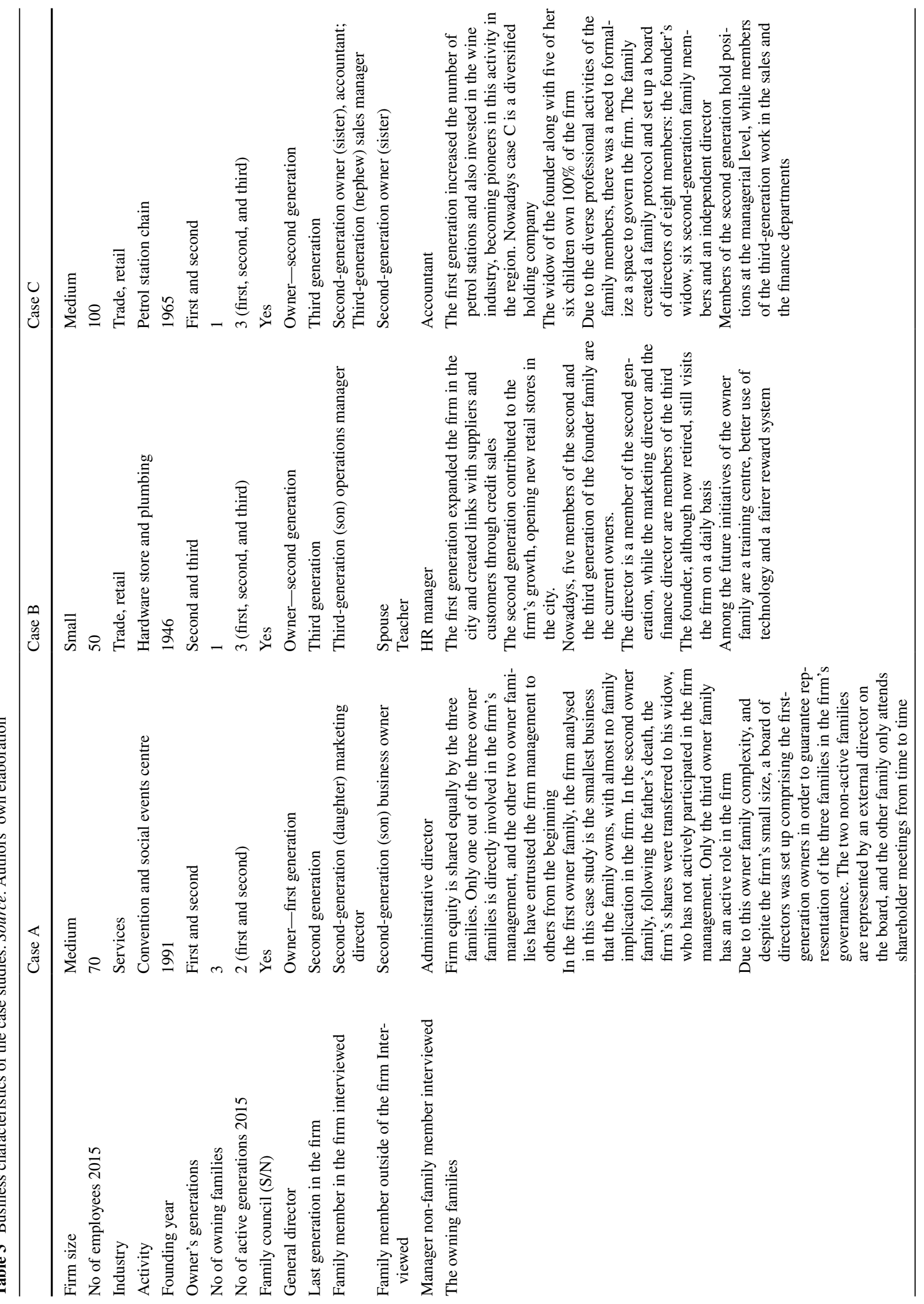


172

C. Aragón-Amonarriz et al.

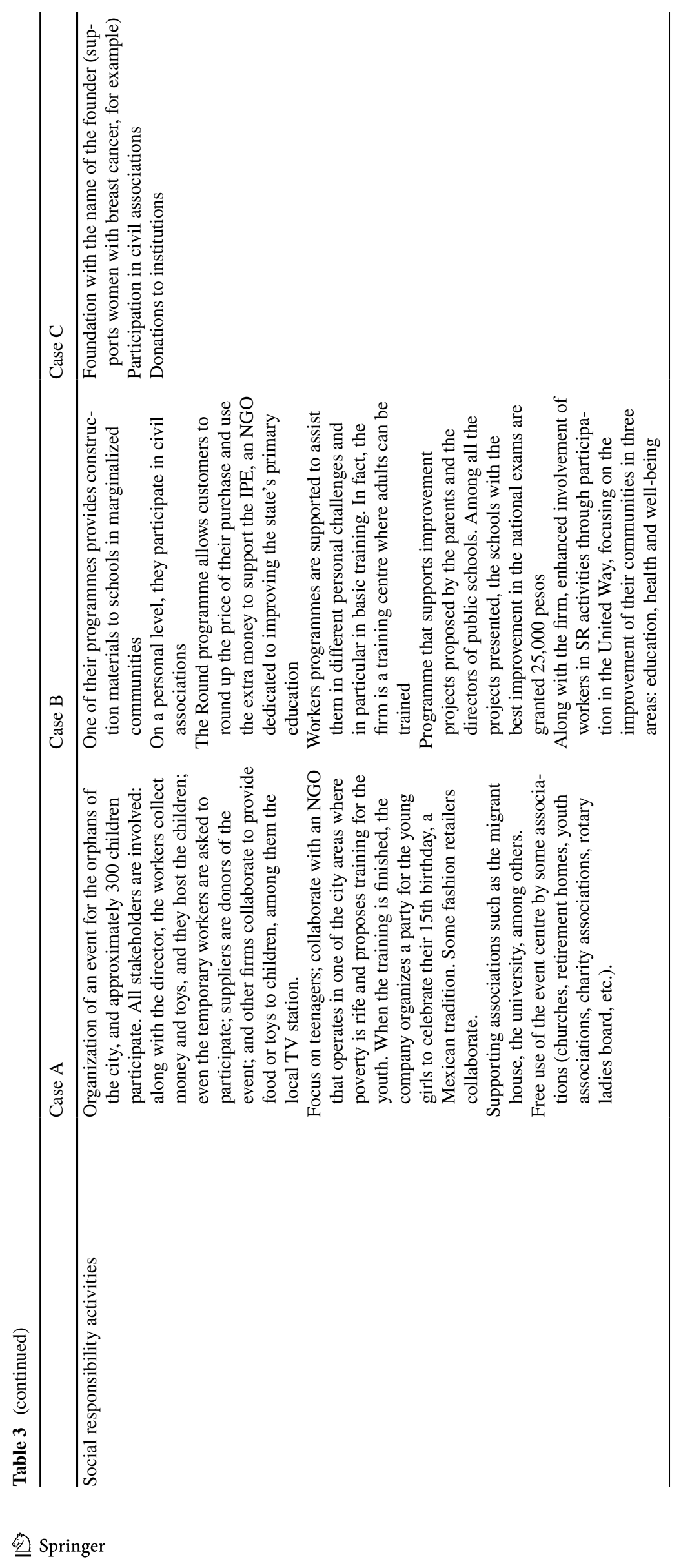


Table 4 Characteristics of interviews. Source: Authors' own elaboration

\begin{tabular}{|c|c|c|c|c|c|}
\hline Date & Duration & Place & People in the interview & Documental support & Other sources \\
\hline 29 October 2014 & $1 \mathrm{~h}$ and a half & General director's office & $\begin{array}{l}\text { General director case A } \\
\text { Researcher }\end{array}$ & $\begin{array}{l}\text { Video camera } \\
\text { Computer }\end{array}$ & $\begin{array}{l}\text { Vision document } \\
\text { Social labour recognitions }\end{array}$ \\
\hline 29 October 2014 & $1 \mathrm{~h}$ and a half & Marketing director's office & $\begin{array}{l}\text { Member of the family work- } \\
\text { ing in the company case A } \\
\text { Researcher } \\
\text { Documenter }\end{array}$ & $\begin{array}{l}\text { Video camera } \\
\text { Computer }\end{array}$ & \\
\hline 29 October 2014 & $1 \mathrm{~h}$ and a half & $\begin{array}{l}\text { Administrative director's } \\
\text { office }\end{array}$ & $\begin{array}{l}\text { Non-member of the family } \\
\text { working in the company } \\
\text { case A } \\
\text { Researcher } \\
\text { Documenter }\end{array}$ & $\begin{array}{l}\text { Video camera } \\
\text { Computer }\end{array}$ & Ethics code \\
\hline 29 October 2014 & $1 \mathrm{~h}$ & Researcher office & $\begin{array}{l}\text { Member of the family not } \\
\text { working in the company } \\
\text { case A } \\
\text { Researcher } \\
\text { Documenter }\end{array}$ & $\begin{array}{l}\text { Phone } \\
\text { Computer }\end{array}$ & \\
\hline 28 October 2014 & $1 \mathrm{~h}$ and $20 \mathrm{~min}$ & Office of the company & $\begin{array}{l}\text { General director case B } \\
\text { Researcher } \\
\text { Documenter }\end{array}$ & $\begin{array}{l}\text { Video camera } \\
\text { Computer }\end{array}$ & $\begin{array}{l}\text { Vision document } \\
\text { Social labour recognitions }\end{array}$ \\
\hline 28 October 2014 & $1 \mathrm{~h}$ and $10 \mathrm{~min}$ & Office of the company & $\begin{array}{l}\text { Member of the family work- } \\
\text { ing in the company case B } \\
\text { Researcher } \\
\text { Documenter }\end{array}$ & $\begin{array}{l}\text { Video camera } \\
\text { Computer }\end{array}$ & \\
\hline 28 October 2014 & $1 \mathrm{~h}$ and $40 \mathrm{~min}$ & Office of the company & $\begin{array}{l}\text { Non-member of the family } \\
\text { working in the company } \\
\text { case B } \\
\text { Researcher } \\
\text { Documenter }\end{array}$ & $\begin{array}{l}\text { Video camera } \\
\text { Computer }\end{array}$ & \\
\hline 28 October 2014 & $1 \mathrm{~h}$ and a half & House of the family & $\begin{array}{l}\text { Member of the family not } \\
\text { working in the company } \\
\text { Researcher }\end{array}$ & $\begin{array}{l}\text { Video camera } \\
\text { Computer }\end{array}$ & \\
\hline 23 August 2014 & $2 \mathrm{~h}$ and a half & General director's office & $\begin{array}{l}\text { General director case C } \\
\text { Researcher } \\
\text { Documenter }\end{array}$ & $\begin{array}{l}\text { Video camera } \\
\text { Computer }\end{array}$ & \\
\hline 26 August 2014 & $1 \mathrm{~h}$ and a half & Office of the company & $\begin{array}{l}\text { Member of the family work- } \\
\text { ing in the company case C } \\
\text { Researcher } \\
\text { Documenter }\end{array}$ & $\begin{array}{l}\text { Video camera } \\
\text { Computer }\end{array}$ & \\
\hline 26 August 2014 & $1 \mathrm{~h}$ & General director's office & $\begin{array}{l}\text { Member of the family not in } \\
\text { the company case C } \\
\text { Researcher } \\
\text { Documenter }\end{array}$ & $\begin{array}{l}\text { Video camera } \\
\text { Computer }\end{array}$ & Pamphlets, letters \\
\hline 28 August 2014 & $1 \mathrm{~h}$ and a half & Office of the company & $\begin{array}{l}\text { Non-member of the family } \\
\text { working in the company } \\
\text { case C } \\
\text { Researcher } \\
\text { Documenter }\end{array}$ & $\begin{array}{l}\text { Video camera } \\
\text { Computer }\end{array}$ & \\
\hline 30 August 2014 & $1 \mathrm{~h}$ and a half & Office of the company & $\begin{array}{l}\text { Member of the family work- } \\
\text { ing in the company case C } \\
\text { Researcher } \\
\text { Documenter }\end{array}$ & $\begin{array}{l}\text { Video camera } \\
\text { Computer }\end{array}$ & \\
\hline
\end{tabular}

firm's ownership. Nevertheless, only one out of the three owner families is directly involved in the firm's management (Table 3).

Case B is a hardware store and plumbing firm set up in 1946. The firm's owners were investors from the USA who first set up a timber merchants in a city on the border with Mexico. They hired a young administrator and after some years the investors sold the business to him. The hardware business then evolved from a traditional shop to a self-service warehouse with value-added services. Nowadays, case 
Table 5 Summary of the structure of the interviews: main dimensions and key issues. Source: Authors' own elaboration

\begin{tabular}{|c|c|}
\hline Dimensions & Key issues \\
\hline Interviewee description & $\begin{array}{l}\text { Interviewee's position in the firm } \\
\text { Interviewee's position in the family }\end{array}$ \\
\hline RFO_Family Ownership Commitment to Stakeholders & $\begin{array}{l}\text { Evidence of the firm's contribution to society in general or to some of its } \\
\text { stakeholders, such as it employees and consumers }\end{array}$ \\
\hline $\begin{array}{l}\text { RFO_Professionalism in Leadership Selection and Human } \\
\text { Resource Management }\end{array}$ & $\begin{array}{l}\text { Evidence of fulfilment of professional requirements to access the firm by } \\
\text { heirs (or the contrary) } \\
\text { Evidence of independence of owner and managerial role (or the contrary) } \\
\text { Evidence of preferential treatment of family members compared with other } \\
\text { non-family members in the same position of the firm (or the contrary) }\end{array}$ \\
\hline RFO_-Professionalism in Organisational and Financial Processes & $\begin{array}{l}\text { Evidence of abusive use of the firm assets (or the contrary) } \\
\text { Evidence of the abusive demands of family members (or the contrary) }\end{array}$ \\
\hline RFO—Responsible Planning for Firm Succession & $\begin{array}{l}\text { Evidence of family agreements to formalize the ownership succession } \\
\text { process } \\
\text { Evidence of family involvement as a whole around the family-firm (or the } \\
\text { contrary) }\end{array}$ \\
\hline RFO_Long-Term Family Vision & $\begin{array}{l}\text { Evidence of the engagement of the family regarding the preservation of the } \\
\text { firm (or the contrary) }\end{array}$ \\
\hline FSC_-cognitive dimension & $\begin{array}{l}\text { Evidence of balancing family, firm and social objectives } \\
\text { Evidence of enhancing intergenerational common vision and the alignment } \\
\text { of interests }\end{array}$ \\
\hline FSC-structural dimension & $\begin{array}{l}\text { Evidence of bonding ties within generations } \\
\text { Evidence of bridging ties across generations or with stakeholders }\end{array}$ \\
\hline FSC—relational dimension & $\begin{array}{l}\text { Evidence of supporting the family value system and its renewal } \\
\text { Evidence of supporting the coherence between values statements and } \\
\text { behaviours }\end{array}$ \\
\hline
\end{tabular}

$\mathrm{B}$ is divided into two independent businesses: the hardware business and the financial department, which offers credit sales to its customers. The third generation of the family is already involved in the company (Table 3).

Case $\mathrm{C}$ is a retail company: a petrol station chain. The founder left his work in a bank and set up his own business at the age of 26 with his savings. In the beginning, case $\mathrm{C}$ was a small business with some petrol stations and vehicle repair shops. More than 50 years later, the family (Table 3 ) is now a diversified holding company, with activities in a variety of industries, including petrol stations, wineries, hotels, gas retail operations and tomato crops. Nevertheless, the main business of the company is the chain of petrol stations.

\section{Cognitive Dimension in the Intergenerational Transmission of RFO}

\section{Balanced Family, Firm and Social Objectives}

Case A declares itself to be socially responsible. It has different programmes involving community engagement, which is a priority for the organization. Specifically, in terms of SR, case A's ethical code (Code of Ethics Report) was developed and applied in collaboration with all the employees.
I am aware of the responsibility I have to my employees, and I feel we are doing something that is worthwhile and meaningful because of the firm's commitment to the community and to the city. The employees also feel this way, and I think they are proud of the firm's social activities. - Case A, director.

In case B, family objectives are formalized in the family's mission. These objectives integrate social and economic issues, which second- and third-generation family members participate in and apply. In particular, the family in case B supports schools and universities in the city and has developed several SR programmes, feeling that social objectives have to be integrated in the firm's activities:

I'm starting to participate in the community [...], I want to focus on two or three projects aside from the company [...]. Nevertheless, I believe that there is no better way to help than by creating jobs. I would like to see this company grow as much as we have seen over the last five years. - Case B, CEO (grandson of founder)

In case $\mathrm{B}$, the priority given to social issues versus bare economic objectives, especially regarding their employees, is clearly established and put into practice whenever the personal circumstances of employees have required it. 
When someone has had a health issue that has affected their professional activity, the reaction of the family was immediate. [...] having caring managers, flexible timetables or being able to work from home $[\ldots]$ is really important. On one occasion there was an employee who had a kidney transplant and the company helped with the medical costs. The family worries about how you are doing in our personal life; they believe that if you have problems, this affects how you are at work. - Case B, nonfamilial employee

Additionally, the family protocol of case B is being developed. In this case, it is noteworthy that despite the significant involvement of family members in business activities, they keep the family and the firm separate. Firm sustainability and preservation was the main criteria in the decision-making regarding the firm's ownership distribution.

My parents made an arrangement in consensus with their children to distribute their properties while still alive. A business valuation was made with the company left to me and the rest of the family properties to my sisters. - Case B, director.

Similarly, the owner family in case $\mathrm{C}$ has defined the firm's long-term goals and vision, and the family's purpose is aligned with these objectives. In the first generation, the social issues were developed in the context of the founder's personal engagement, assisting and helping in the case of each one of the requests he received.

The founder has always put into practice SR, even when it was an unknown issue. - Case $\mathrm{C}$, director.

The second generation institutionalized SR activities in 2001 by creating a family foundation, whose mission is to contribute to the community's needs as the founder did (see their Facebook page). They also established family policies in terms of allocated utilities, family expenses related to business policies and family assets administration, always with the aim of preserving the firm. This institutionalization does not mean that the family is not personally involved, but it does preserve its sustainability. Nowadays, the firm considers that:

...social, business and family responsibilities go hand in hand; firms are people, and profitability cannot become more important than human issues.

- Case C, director.

Environmental objectives remain the only exception. In the three cases, the families consider environmental issues only in terms of legal obligations, not as an issue of engagement to be assumed by the family's SR.
Intergenerational Common Vision and Alignment of Interests

The alignment of interests is often at stake at critical moments, especially when the firm's economic situation suffers.

Several years ago, we had a rather difficult economic situation. We knew we could not raise salaries, but nor did we want to be forced to lay off employees. We talked with everyone and we reached an agreement: the family cancelled all their benefits expectations, but nobody was dismissed. - Case A, director.

In case $\mathrm{A}$, the director and the other family owners proposed to the second generation, currently the functional managers, that they lead the firm in the future. The second generation's candidate considered this opportunity, but due to her personal plans, she saw herself in a secondary role in the firm rather than as the leader. The third generation is still too young to work in the FF.

It is a crucial issue. I am trying to find different alternatives, family and non-family candidates. It is still unresolved but we hope we will find a successful solution. - Case A, director.

The family owners try to reach a balance in the long term between the aspirations of members of the different generation and the requirements of the firm. Because of this willingness to find a balance, the family is looking for an external manager to preserve the life objectives of family members, the firm's continuity and care for the stakeholders. In this sense, the professional careers led by the other family members outside of the firm have been respected.

As stated before, the FF protocol in case B has begun but is still not finished. Constructive discussions and further dialogue are required due to the current relevance of ambitious objectives of the new generations.

I would rather not spend as much time [as my father] out of the company. [...] I believe that as a business, we could be bigger. - Case B, CEO (grandson of founder)

Regarding case C, family consensus is reached in family council meetings. For instance, there is a consensus about maintaining the current FF values. Encouraging engagement of the third generation is a priority. Therefore, potential successors are specifically trained (in values and leadership) and have to work in all areas of the organization to develop a holistic view of the firm. They are also invited to participate in different activities launched by the foundation, and contribute to the community of the region, while family values are transmitted to the third generation. Additionally, when the objectives of the firm 
and the family clash, they claim that sharing and explaining decisions is the best way forward. The balance of the interests in conflict is solved thanks to the family values (relational dimension) which provide guidelines in case of a controversial position, and thanks to the fluent communication among the people involved (structural dimension).

Recently a top management position in the company was open. On the list of possible candidates was my older nephew and people from outside the company. It was not easy but obviously he didn't get the position; he still has to gain experience. - Case $\mathrm{C}$, family member

Therefore, concerning the cognitive dimension, the social objectives in all three firms have been clearly stated, accepted and integrated in the firm's purpose since the founding of the company. The balance of interests is supported by the communication among family members (structural dimension) and the shared family values (relational dimension). In all the cases, the firms are committed to social activities. This social engagement is rooted in the examples of the founder, who realizes his/her fortune in life, and is at the basis of caring for others who are less fortunate. This duty is assumed by the family as a question of honour. In this context, the balance between family, business and social objectives has a long-term and intergenerational approach. Nevertheless, potential intergenerational conflicts have been identified in all three cases regarding the cognitive dimension of RFO, mostly related to the intergenerational common vision and alignment of interests. In case A, personal and firm or intergenerational interests were opposed when, due to her personal objectives, the manager (second generation) refused to become director, in contrast to the objectives of the first generation and the firm. Social versus economic issues were in conflict when some third-generation members questioned the modus operandi of their predecessors in case B or when successors were not hired by the firm in case $\mathrm{C}$.

\section{Structural Dimension in the Intergenerational Transmission of RFO}

\section{Bonds Between Family Members}

Communication among the family members in case $\mathrm{A}$ is quantitatively and qualitatively abundant and fluent. Personal contact between the director and her daughter, who is managing a functional area of the organization, as well as among the owners from different generations in the shareholder council allows for direct and fluent intra- and intergenerational communication.
You would never know that they are mother and daughter, as there is no preferential treatment. On the contrary, sometimes the director gives her daughter the hardest tasks to deal with. - Case A, family member in the marketing department.

However, strong bonding SC among family members can sometimes be a menace to positive SC development. Consequently, policies or practices should be set up to control nepotism, as happened in case B.

The director's nephew asked for special treatment because he was part of the family. The director's response was that he should be considered like any other employee, and that is exactly what we did - Case $B$, human relations manager, non-owner family member.

One of the main events in the relational history of case $\mathrm{C}$ was when one of the brothers from the current generation left the firm. This incident threatened family stability, but the director handled the situation well, preserving family interests and maintaining a healthy relationship with the brother who had left. This incident concerned the whole family not only the family members active in the firm. Consequently, the nieces and grandchildren were informed of the situation to be able to understand it and to maintain family ties with the outsider branch.

My uncle's departure from the firm is a great example of how family relationships and unity remain, even if things have changed in the FF. It was handled amazingly well; firm issues were completely separated from family issues, and everything is as it was in my family before my uncle's departure. I thought it was going to break up the family, but it was handled very carefully and family unity $[\ldots]$ was preserved. That was thanks to my grandfather and my grandmother. - Case $\mathrm{C}$, third-generation family member.

This family unity has guaranteed that "leaving" the business does not mean "leaving" the family. Being an active member of the firm is not a prerequisite to be considered a family member. The association with the firm remains an option that is free for family members.

A relevant issue for the FF is to constantly ensure family unity. - Case C, family member.

Family relationships are based on communication. Given the increasing dimension and complexity of the family members' involvement with the firm or the foundation, communication has become formalized. The family-firm separation is guaranteed thanks to the family and the firm's governing bodies-(a board of directors and a family council) and to the family protocol. 
Bridging Ties Across Family Generations and With External Stakeholders

The owner families in case A are not equally involved in the firm. Nevertheless, this asymmetry does not imply a disassociation on the part of the members not involved in the firm's management. On the contrary, they support the current director in her management and there is fluent intergenerational communication. Additionally, relationships with external stakeholders are also influenced by the firm's social approach.

We spread our social spirit among our employees, customers and suppliers. - Case A, director.

Case B family enjoys a great social reputation in the community. Starting with the founder generation, they have participated in the city's hospital and school councils.

This firm is committed to the community and to us, the employees, which is why the it has a strong reputation for stability and transparency, and this is well recognized by the community. - Case B, non-family HR manager.

This high level of involvement with the community results in the success of the firm's SR programmes which address community needs and which benefit from high participation. The family members as individuals are also committed to different social action programmes, and thus, the family name itself has a great reputation as a benefactor of the community.

The family have received several recognitions over the years. On one occasion the founder appeared on TV for his involvement with community needs. Wife of the director of case $\mathrm{B}$, who has no position in the firm.

Concerning this dimension, the director of the firm in case $B$ realizes the importance of involving the third generation in the firm. Welcoming the third generation has required the formalization of the family-firm relationship. To be able to achieve agreement on family decisions related to the business (cognitive dimension), a family council has been created. In the beginning, the successor and the director participated in it, but nowadays three external advisors are included to assist the family in their business decisions. Therefore, the third generation receives direct reports of current decisions regarding the business, thus increasing their knowledge of the organization.

The unity of my father-in-law and mother-in-law is really important for this family, and we admire them a lot. - Wife of the director in case B, who has no position in the firm.
Communication in case B concerns the three generations of the founder family, even if they are not working in the firm. The family members participating in the business meet at the firm council, and the non-participating family members are also informed about the firm and the SR activities in which they collaborate.

Related to the intragenerational and intergenerational relationships, the family owners in case $\mathrm{C}$ have promoted these relationships since the founding period (family Sundays, family shared holidays and a family bus for the grandchildren's school commute). In doing so, the family helps to balance family and work life while helping the children to share everyday routines. The shared family farm house is usually the place for these get togethers, facilitating intergenerational exchange and owner family meetings. These relationships are also a relevant way to share values (relational dimension), both in a spontaneous way (WhatsApp group among brothers and sisters of the same generation) and in a formal way (the family protocol).

An example of this separation is that the family intends to maintain formalized firm entry conditions for the third generation. Among the requirements for integrating the FF for all the family's potential successors are participating in the foundation, having professional experience outside of the FF, or participating in a formal programme of English training and foreign travel.

Something that I see in the family and that is transmitted to the company is that family and business issues are separated very well. On the other hand, I see that this is difficult for the third generation and is something we must work on. - Case $\mathrm{C}$, grandson of the founder, working in the firm.

Related to the structural dimension, the families studied facilitate an intensive and positive relationship among members of the same generation and of different generations. Creating initiatives to maintain personal and informal contact among family members, setting up family and firm councils, and working in a family protocol are some of the strategies the families develop to enhance family unity (relational dimension). This unity preserves the family's way of behaving as well as harmonizing the attitudes of family members towards the sustainability and SR of the firm (cognitive dimension). Additionally, the families try to separate these two different areas, avoiding confusion between the family and the firm, as shown in case B and C. Finally, these relationships are not limited to the family and the firm in that they cross organizational boundaries and over to the other stakeholders. In the three cases, the current reputation is built on the care devoted by the family to the stakeholders across generations. This care is based on family honour rather than on commercial interests. 


\section{Relational Dimension in the Intergenerational Transmission of RFO}

\section{Consistency of Value System and Its Renewal}

In case $\mathrm{A}$, the founder has been the director of the firm since the beginning, leading and leaving a personal mark on the firm. Thanks to the director's innate ability, the growth of the business and the shared family values, such as respect and freedom (relational dimension), the intragenerational harmony among the family owners has been enhanced. This harmony and trust has allowed for the separation of the family and the firm and the clarification of the nature of the relationships in each of these areas.

I remember that once, when this company was 3 or 4 years old, I was very young and I used to come with her (the director) to different events. On one occasion, she was with one of the partners' sons when an unexpected problem arose; she was overwhelmed and she cried. That left an impression on me. Of course, no matter how strong you are, sometimes you break down. But I saw her stand up and continue "we dust ourselves off, as she tells us, 'and carry on. - Daughter of the director in case $\mathrm{A}$, working in the firm in a managerial position.

Case B is based on family values. Due to the lack of managerial training of the founder, the firm's SR activities focus on improving the training of community members. According to the director, the firm-community relationship cannot be separated.

[It] ... is a social vision that comes from the founder and that is highly rooted in the family. - Case B, director.

Regarding how the family in case B transmit their values, they are followed by the example set by the first generation. Constant work and sacrifice are part of the founder's example who, despite getting older, maintains daily contact with the firm. Founding values are normally present in interactions between family members. Honesty, one of the firm's pillars, has become an acquired value among current family and workers. Service to the community also continues, with first and second generations involved in associations and city boards, and the director having participated in the city government. Maintaining family unity is still a priority. First and second generations participate in family life, reserving time to spend with their relatives, and thus, the third generation understands the importance of putting time aside for family. In case B, showing care and kindness for both workers and stakeholders is an enduring value that each generation's leadership has used to create an atmosphere of warmth. The behaviour of the owner family is guided by unity, honesty, a consistent work ethic and being involved. This coherence is appreciated by the workers and increases the involvement of the firm's stakeholders. Furthermore, these values support the objectives and vision of the firm (cognitive dimension) and are promoted by a high level of communication across generations (structural dimension).

One day, my son said that he wanted to change the car he had for a Mercedes-Benz. I replied by asking him three questions: What are you trying to show by having a Mercedes? Why don't you try something less flashy? What does a car like that say about us to our collaborators? And my son answered: I knew you would say something like this, and you are right. The value of simplicity is an important one. - Case B, 1 director.

In case $\mathrm{C}$, the values of the owner family (respect, hard work, austerity and separating family and firm into two areas) are transmitted through the founder's examples and hard work. Ethics has become part of the FF's culture.

The family unit is the backbone and it has been preserved by adapting to different situations throughout the family history of case C. First, the idea that the firm is an asset that the family has to protect and be grateful for is a constant value across the family's generations. Second, hard work and austerity are important values that require the respect of the organization and its assets, even if the family has the final power over the firm. Consequently, an egalitarian relationship with workers, without favouritism, is expected within each generation.

He had the vision of putting us to work very young. My brother and I have worked in the gas station since we were 7 years old. During our holidays, I saw how my friends had a great time and I was working. In fact, I was always working during my childhood and youth. My father used to say, 'There is no free lunch; if you want something you must work for it'. - Case $\mathrm{C}$, director.

\section{Coherence Between Statements and Behaviour Regarding Values}

Concerning the transmission of values in case A, the first generation has transferred family values to the firm and to the successors in the firm. The values of service, work devotion, perseverance and sensitivity to people are incorporated by the director in her current behaviour and are present in several examples given by interviewees.

In the formative years, I try to instil in my children and grandchildren a sense of responsibility, and also in the employees. - Case A, director. 
The coherence between the firm's values in terms of statements and actual behaviour is visible in the social programmes the firm develops (as listed on its web page) and in the director's decisions related to employee salaries and well-being. An example of the values in practice is that during periods of crisis, wages were not increased and dividends were not distributed. The values are applied in very particular initiatives led by the first generation.

In the family in case B, the third generation's skills and values needed to lead the firm in the future (relational dimension) are developed through example and personal contact.

Example teaches. I saw my father always working or doing things for his community [...]. And he always looked after us, $[\ldots]$ and he always had time when we wanted to do something. - Case B, director (grandson of founder).

In case $\mathrm{C}$, the family has formalized some policies with respect to the third generation's integration into the firm such as the participation of successors in the $\mathrm{C}$ foundation. The purpose of this family policy is to train the successors and to transmit family values and help them evolve, so they are able to welcome the new generation in an updated business context.

These cases show that the growing complexity of families, such as the addition of new members, and intergenerational differences, requires a focused effort on maintaining values. In fact, to prevent value outliers, the families have developed different strategies such as providing relevant leadership examples in dramatic situations (cases A, B and $\mathrm{C}$ ), and applying the integrative policies of a predecessor generation (case C). The FFs' vision and objectives (cognitive dimension) are the application of the family value system (relational dimension). In these processes, the value system of the family is configured and updated around their core values. The family's honour depends on sustaining these values across generations.

Table 6 presents a summary of the deliberate dynamics which have been identified in the transmission of RFO in each case analysis. The strategies identified are especially valuable in critical periods (such as during periods of succession or when the family/firm grows) to help avoid opportunistic behaviour and intergenerational conflicts. The balance between business, social and family interests (cognitive dimension) is facilitated by the fluent communication among the family members and the stakeholders (structural dimension) as well as the common values shared by the family (relative dimension). Preserving the balance between the social, personal and business interests involved in the firm (cognitive dimension) and family values (relational dimension), supported by clear and direct communication or dialogue strategies among family members (structural dimension), allows the social approach and family values to be shared in the long term.

\section{Discussion}

In an attempt to further the previous work about the SR of family SMEs, we focus on the family who owns the firm instead of analysing the firm itself or comparing family and non-family issues, such as values, culture and ethical behaviour (Duh et al. 2010) or stakeholder approach (Bingham et al. 2011), and analyse the role of FSC in the transmission of RFO across generations. We use FSC dimensions to classify the problems and strategies existing in a positive RFO transmission, and we propose a theoretical rationale to understand them. The first finding shows that families sustaining SR in family SMEs over time have similar strategies to overcome the problems they face (such as intergenerational conflicts, losing long-term perspective, nepotism, family break-ups, family and firm confusion, and inconsistency between stated values and behaviour). These families/cases balance family, business and social objectives, applying a long-term and intergenerational perspective when aligning the interest and the social vision of family members, thus ensuring successful RFO transmission across generations. The context of Mexican SMEs in which family is a relevant economic and social actor (Erdener 2009) offers a suitable opportunity to observe this issue. Although minimally discussed in the ethics literature, ethical supports for the SR of family SMEs are critically important to the ethics literature (Duh et al. 2010), and therefore, this first result is a legitimate and original contribution in this field.

The relevance of the FSC factors identified in the framework as a means to sustaining RFO across generations has been contrasted (see Table 6). Nevertheless, the evidence collected has helped us identify one of the main contributions of this paper: that the transmission of RFO requires building a dynamic intra- and intergenerational FSC based on the sum of its dimensions: cognitive, structural and relational. The interconnections among the three dimensions require a holistic perspective from family members.

First, the cognitive dimension itself is not enough to sustain RFO across generations. If new generations are not aware of the future benefits they will receive from responsible behaviour, mutual reciprocity based on long-term common interests is challenged (Wade-Benzoni 2002). One strategy has been for the families to create common spaces in which exchanges between the generations can occur, such as the family council of cases B and C (structural dimension), which promotes intergenerational dialogue about relevant topics (relational dimensions). The transmission of the cognitive dimension is supported by FSC as a whole. 


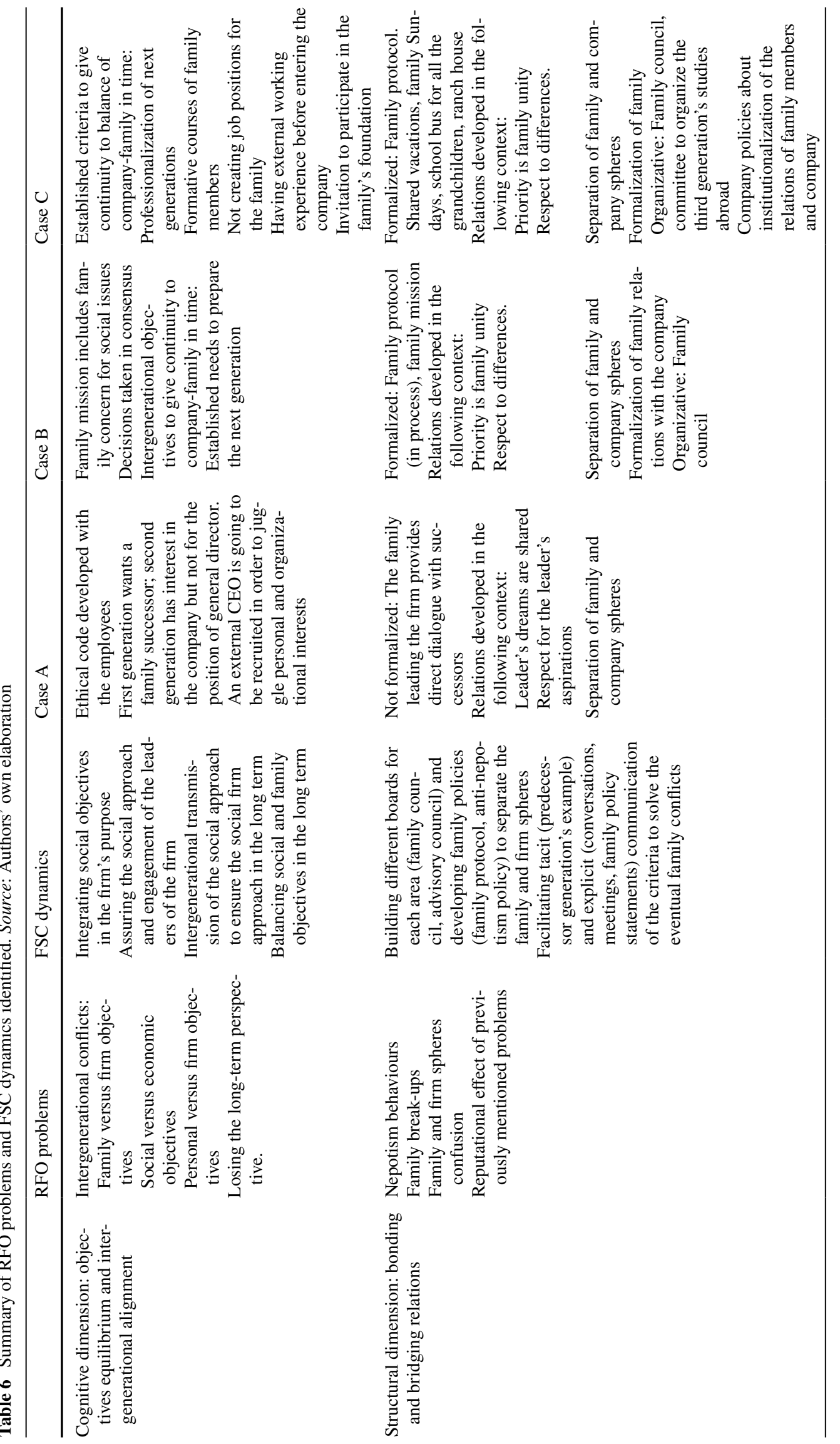




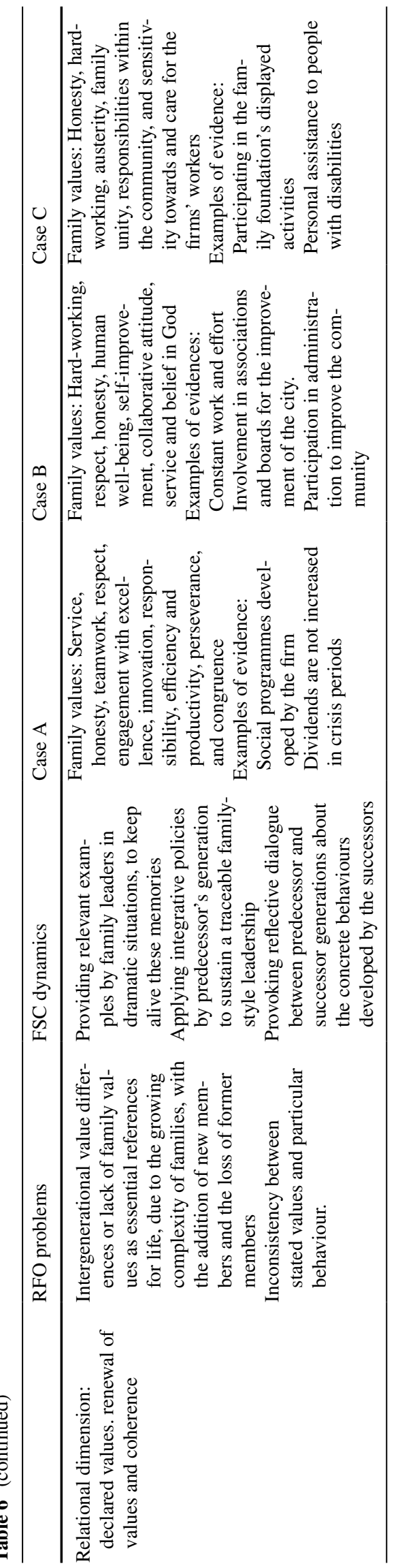

Second, and related to the structural dimension, we observe that the families facilitate intensive positive relationships among members of the same generation as well as the other generations, thus bridging ties. Relationships not only occur within the firm but also surpass it to include the development of family relationships outside of the firm. These relationships, founded on mutual trust and free engagement with the FF (relational dimension), have been nurtured since the childhood of each generation, and even include the younger third generation (shared bus to school, Sunday lunches at the family home). The development of these relationships has evolved over time, increasing the level of formalization as the family becomes more complex. At the first level, personal or professional meetings are held spontaneously, enhancing horizontal relationships. At the second level, meetings in response to a particular problem or need take place. And finally, meetings are held to seek consensus regarding a family interest, such as when case C established certain family policies regarding the third generation's integration into the firm (cognitive dimension). At this last level, formal and informal communication is abundant in both areas - the family and firm. Formally, a family mission statement is established, and family members are required to attend meetings with precise objectives. Informally, different strategies are developed at different stages.

Third, with respect to the relational dimension, the cases analysed show that the personal values of the first generation lead the social activity of the family leader and the firm. Sustainable business and family continuity and performance are based on these values (Hammann et al. 2009). The personal values established in the first generation are subtly present throughout all three firms: honesty, hard work, austerity, family unity, responsibilities within the community and sensitivity towards and care for the firms' workers. The predecessor generation is actively involved in transmitting these values to successor generations by both example and direct communication (structural dimension). The values are transferred through the leader's example (Adams et al. 1996). The founder acts as a reference, a personal and professional model to the members of the firm and the family, to ensure coherence between statements and behaviour regarding values (Perrini and Minoja 2008). Consequently, family SMEs are willing to participate more proactively in SR (Bingham et al. 2011). Thus, family SMEs are based on the founder's values, such as in case A when, after having broken down, the director stood up and continued working. The family members look up to his or her experience, and the main narratives and statements regarding values and mission are quoted across the generations. The transmission of the value system is supported by the family members' testimony. The predecessor generation illustrates what is expected from the successor generations and firm members, outlining what the predecessor generation is ready to give to them in return. In 
this sense, education and socialization are the ways in which the values of the family are transmitted (Tapies and Fernández Moya 2012). Among others, the examples are equal treatment of family members and non-members at work (fairness) and the lack of increasing dividend demands when wages are not increased due to economic crisis (engagement and sacrifice). In this sense, non-family workers become a reference to contrast the behaviour of family members, and in all the cases, a family-style leadership is traceable.

However, the observed cases show that the founder's legacy and example can start to blur, leading to preserve an individual rather than a collective perspective embedded in RFO (as happens in case B, when a successor desires to acquire an expensive car, against the family's principle of simplicity). Regarding the social mission and continuity of the firm, successor generations are invited to put into practice the values (cognitive dimension) through dialogue, family activities, formalized structures (structural dimension), or by the development of policies and programmes (relational dimension).

Constant recurring references to the founder's behaviour and values can be seen throughout the data gathered. In this process, if the predecessors' dynamic is based on giving more than is received and therefore the fundamental rule of economic exchange is broken (Godbout 1998), the voluntary engagement of successors in the family mission will be promoted (Wade-Benzoni 2002). Otherwise, the unlikely probability of benefiting from a responsible behaviour in the future would damage the intergenerational mutual reciprocity. In this sense, the second finding comes from all the cases analysed, where it is observed that RFO transmission is based on a particular quality: honourableness. Following A $\beta$ länder (2013), this attribute [defined by Cicero as following human duties, which means living a virtuous life and striving for the common good (Cicero 2009a, I, 4)] is a precondition of a good reputation and it does not depend on whether or not this trait helps generate profit. Honourableness crystallizes the way each family member is expected to behave. It is an individual duty, a precondition (A $\beta$ länder 2013) for the service of something higher: the reputation of the family and the firm. In this sense, honourableness nurtures the family's reputation and evokes respect from stakeholders and family members, such as in case B (a local firm well recognized by the community) in which the nonfamily director explains that the firm's commitment to the community and to the employees is the reason for the firm's strong reputation for stability and transparency. This family's honourableness is perceived in the cases as an immanent attribute that transcends the family while also acting as a driver of RFO transfer, aiming to preserve this attribute that is immanently associated with the family. In the transmission of RFO, it serves as both an objective and an asset that has to be preserved. However, this attribute goes beyond the concept of "survivability capital" understood as the strong bonds of internal SC that characterize owner families (Sirmon and Hitt 2003).

In the observed cases, honourableness is established by the founder's example, promoted by family members and expected of the new generations. The family realizes its good fortune in life and self-imposes honourable behaviour. Keeping the founder figure alive in the minds of family members and firm workers as well as highlighting his or her honourable behaviour seems to be helpful in the transmission of RFO across generations. To avoid this degenerative process, as Long (2011) and Wade-Benzoni (2002) state, previous interactions among family members serve as a frame of reference, an example of honour for future interactions. The deliberate dynamics developed by the predecessors' governance to preserve the honourableness of the family [positioning it as a heritage or a gift and not as a burden (Godbout 1998)] enhance the involvement of future generations (Marques et al. 2014) and are at the basis of a successful transmission of RFO.

Additionally, a third main finding drawn from the evidence is that the institutionalization of RFO dynamics stands out as a necessity for maintaining the FSC factors already present in these growing family SMEs. What we have seen is that in the early development stages of these firms, due to their limited size, the owner family has a close relationship with its stakeholders, maintaining informal and direct contact (Spence 1999). In this context, the family owners personally concern themselves with other family members' behaviour which is visible and therefore has a direct impact on the FF's image and reputation (Zellweger et al. 2013). Once the SMEs start growing and a larger number of family members participate in the firms, problems arising from asymmetric power (Mitchell et al. 2011) and dysfunctional power arrangements within the firms (Leana and Van Buren 1999) can lead to a decreasing unity in the families and the firms (Salvato and Melin 2008). Therefore, as a family grows and the founder's example blurs, the direct and informal relationships which are typical in the founding stage have to be replaced by formalized mechanisms, as has happened in cases B and C (structural dimension) to deter potential opportunistic behaviour (Mustakallio et al. 2002). On the other hand, as a family grows and become more complex, family-firm conflicts require SMEs' governance and managerial professionalization as well as the formalization of family SMEs values (relational dimension) in order to guarantee direct intergenerational contact (Tapies and Fernández Moya 2012). That is, factors related to the three FSC dimensions have to interact together in order to sustain RFO over time.

In our paper, we contribute to the debate about the role played by the family in family SMEs for sustainable SR, presenting three main contributions to the academic field. First, 
we examine the FSC approach to understand the transfer of RFO in family SMEs. In particular, we enhance the systemic perspective needed to understand the effect of FSC dimensions in the transmission of RFO. Second, we identify a new concept of family honour as a driver of FSC dimensions in sustaining the transmission of RFO. Third, we specifically address the context of growing family SMEs and identify the institutionalization required by growing families to face the potential problems intrinsic to RFO transfer. In addition to all three contributions cited above, we identify the problems and strategies involved in RFO transmission across generations. Our findings show that the holistic approach is required to successfully reinforce FSC in family SMEs, and we provide a useful source of recommendations and best practices which can illuminate the experiences of practitioners facing RFO intergenerational processes.

The paper does, however, contain certain limitations. First, we focus only on family owners, categorizing them according to their generation or involvement in the FF. Other classifications are indeed possible. For instance, the typology of owner-managers' attitude towards their business (Birley 2001) could be applied to family owners to analyse whether these new family clusters could make relevant contributions. Second, even if non-family members working in the FF were included, interstakeholder exchange has not been specifically analysed. In particular, the role of external stakeholders in RFO sustainability could be considered in future research due to the impact of firm reputation on family reputation (Zellweger et al. 2013). In addition, including interviews with internal stakeholders (such as non-family members) would complete the kaleidoscopic perspective we have presented in this paper. Third, successful case studies have been selected. However, family SMEs that have abandoned socially responsible activities or have failed RFO transmission could provide the limits of FSC in preserving RFO. In this sense, the research can be enriched by considering the role of stability, interactions, interdependence and closure as relevant drivers of FSC (Arregle et al. 2007). Fourth, although intergenerational reciprocity has been considered in this paper, this concept can be analysed in more depth. We propose that future research consider the typology of reciprocity, such as moral reciprocity, mutual reciprocity, univocal reciprocity and intergenerational reciprocity (Janjuha-Jivraj and Spence 2009). Finally, the paper's main limitation is the specificity of its cases, an issue that should be addressed in the future by applying the framework to other industries and locations. In fact, the selected industries and geographical locations of the case studies may influence the results and differ from family SMEs operating in other activities or geographical areas. Nevertheless, at this stage, important general lessons have emerged regarding the benefits of delving deeper into the FSC that supports the transfer of RFO from generation to generation.
Acknowledgements Thanks are due to the family-firms' leaders and members that have provided the required evidences for this paper. Additionally, we acknowledge financial support from the Basque Government Department of Education Language Policy and Culture.

\section{Compliance with Ethical Standards}

Conflict of interest All authors declare that they have no conflict of interest.

Informed Consent Informed consent was obtained from all individual participants included in the study.

Open Access This article is distributed under the terms of the Creative Commons Attribution 4.0 International License (http://creativecommons.org/licenses/by/4.0/), which permits unrestricted use, distribution, and reproduction in any medium, provided you give appropriate credit to the original author(s) and the source, provide a link to the Creative Commons license, and indicate if changes were made.

\section{References}

Adams, J. S., Taschian, A., \& Shore, T. H. (1996). Ethics in family and non-family owned firms: An exploratory study. Family Business Review, 9(2), 157-170.

Adler, P. S., \& Kwon, S. (2002). Social capital: Prospects for a new concept. Academy of Management Review, 27, 17-40.

Aragon, C., \& Iturrioz, C. (2014). Responsible family ownership in small- and medium-sized family enterprises: An exploratory study. Business Ethics: A European Review, 25, 75-93.

Aragón, C., Narvaiza, L., \& Altuna, M. (2015). Why and how does social responsibility differ among SMEs? A social capital systemic approach. Journal of Business Ethics, 138(2), 365-384.

Aronoff, C. E., \& Ward, J. L. (2001). Family business values: How to assure a legacy of continuity and success (No. 12). Family Enterprise Publisher. New York: Palgrave Macmillan.

Arregle, J. L., Hitt, M. A., Sirmon, D. G., \& Very, P. (2007). The development of organizational social capital: Attributes of family firms. Journal of Management Studies, 44(1), 73-95.

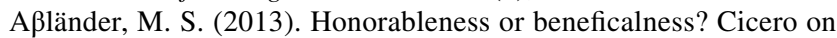
natural law, virtues, glory, and (corporate) reputation. Journal of Business Ethics, 116(4), 751-767.

Baxter, P., \& Jack, S. (2008). Qualitative case study methodology: Study design and implementation for novice researchers. The Qualitative Report, 13(4), 544-559.

Belausteguigoitia, I. (2007). La influencia de la familia en las organizaciones familiares mexicanas. Revista Dirección Estratégica, Instituto Tecnológico Autónomo de México, 21.

Berent-Braun, M. M., \& Uhlaner, L. M. (2012). Family governance practices and teambuilding: Paradox of the enterprising family. Small Business Economics, 38(1), 103-119.

Berrone, P., Cruz, C., \& Gomez-Mejia, L. R. (2012). Socioemotional wealth in family firms, theoretical dimensions, assessment approaches, and agenda for future research. Family Business Review, 25(3), 258-279.

Berrone, P., Cruz, C., Gomez-Mejia, L. R., \& Larraza-Kintana, M. (2010). Socioemotional wealth and organizational response to institutional pressures: Do family controller firms pollute less? Administrative Science Quarterly, 55, 82-113. 
Betancourt, A., Arcos, S., Torres, A., \& Olivares, L. (2012). Empresas familiares. Tlatemoani, Revista Académica de Investigación 9. http://www.eumed.net/rev/tlatemoani/09/emvb.html.

Bettenhausen, K. L., \& Murninghan, J. K. (1991). The development of an intragroup norm and the effects of interpersonal and structural challenge. Administrative Science Quarterly, 36(1), 20-35.

Bingham, J. B., Dyer, W. G., Jr., Smith, I., \& Adams, G. L. (2011). A stakeholder identity orientation approach to corporate social performance in family firms. Journal of Business Ethics, 99(4), $565-585$

Birley, S. (2001). Owner-manager attitudes to family and business issues: a 16 country study. Entrepreneurship Theory and Practice, 25, 63-76.

Block, J. (2010). Family management, family ownership, and downsizing: Evidence from S\&P 500 firms. Family Business Review, 23(2), 109-130.

Bubolz, M. (2001). Family as source, user, and builder of social capital. Journal of Socio-Economics, 30, 129-131.

Cabrera, K., \& Santana-Martín, D. J. (2004). Governance in Spanish family business. International Journal of Entrepreneurial Behavior \& Research, 10(1/2), 141-163.

Cárdenas, J. (2014). Are Latin America's corporate elites transnationally interconnected? A network analysis of interlocking directorates. Global Networks, 15(4), 424-445.

Carney, M. (2005). Corporate governance and competitive advantage in family-controlled firms. Entrepreneurship Theory and Practice, 29(3), 249-265.

Cennamo, C., Berrone, P., Cruz, C., \& Gomez-Mejia, L. R. (2012). Socioemotional wealth and proactive stakeholder engagement: Why family-controlled firms care more about their stakeholders. Entrepreneurship Theory and Practice, 36, 1153-1173.

Cennamo, C., Berrone, P., \& Gomez-Mejia, L. R. (2009). Does stakeholder management have a dark side? Journal of Business Ethics, 89(4), 491-507.

Chua, J. H., Chrisman, J. J., \& Sharma, P. (1999). Defining the family business by behavior. Entrepreneurship Theory and Practice, $23,19-40$.

Coleman, J. S. (1988). Social capital in the creation of human capital. American Journal of Sociology, 93, 291-321.

Cruz, C., Larraza-Kintana, M., Garcés-Galdeano, L., \& Berrone, P. (2014). Are family firms really more socially responsible? Entrepreneurship Theory and Practice, 38(6), 1295-1316.

Deniz, M. C., \& Cabrera, M. K. (2005). Corporate social responsibility and family business in Spain. Journal of Business Ethics, 56(1), $27-41$.

Distelberg, B., \& Sorenson, R. L. (2009). Updating systems concepts in family businesses: A focus on values, resource flows, and adaptability. Family Business Review, 22(1), 65-81.

Duh, M., Belak, J., \& Milfelner, B. (2010). Core values, culture and ethical climate as constitutional elements of ethical behaviour: Exploring differences between family and non-family enterprises. Journal of Business Ethics, 97(3), 473-489.

Dyer, W. G., \& Whetten, D. A. (2006). Family firms and social responsibility: Preliminary evidence from the S\&P 500. Entrepreneurship Theory and Practice, 30(6), 785-802.

Eisenhardt, K. M. (1989). Building theories from case study research. Academy of Management Review, 14(4), 532-550.

Erdener, C. (2009). Family business and industrial groups in Mexico. Journal of International Business and Economics (listed in Cabell's Directory of Refereed Publications), May 2009.

Espinoza, T. I., \& Espinoza, N. F. (2012). Family business performance: Evidence from Mexico. Cuadernos de Administración, 25(44), 39-61.

Gallo, M. A. (1998). La sucesión en la empresa familiar. Colección Estudios e Informes, $\mathrm{n}^{\circ} 12$. Servicio de Estudios de La Caixa.
Gallo, M. A. (2004). The family business and its social responsibilities. Family Business Review, 17(2), 135-149.

Godbout, J. T. (1998). The moral of the gift. The Journal of SocioEconomics, 27(4), 557-570.

Godos-Diez, J. L., Fernández-Gago, R., \& Martínez-Campillo, A. (2011). How important are CEOs to CSR practices? An analysis of the mediating effect of the perceived role of ethics and social responsibility. Journal of Business Ethics, 98(4), 531-548.

Gómez-Mejía, L. R., Haynes, K. T., Núñez-Nickel, M., Jacobson, K. J., \& Moyano-Fuentes, J. (2007). Socioemotional wealth and business risks in family-controlled firms: Evidence from Spanish olive oil mills. Administrative Science Quarterly, 52(1), 106-137.

Habbershon, T. G., \& Williams, M. L. (1999). A resource-based framework for assessing the strategic advantages of family firms. Family Business Review, 12(1), 1-25.

Hamilton, S., \& Goodfrey, J. (2007). Preparing the next generation for the responsibilities of ownership. Journal of Wealth Management, 10(3), 8-16.

Hammann, E. M., Habisch, A., \& Pechlaner, H. (2009). Values that create value: Socially responsible business practices in SMEs: Empirical evidence from German companies. Business Ethics: A European Review, 18(1), 37-51.

Hernandez, M. A. (2012). Las empresas familiares ¿empresas diferentes? Revista de la Universidad Autónoma del Estado de Hidalgo, 1(1).

Hernández-Sampieri, R., Fernandez-Collado, C., \& Baptista, P. (2006). Metodología de la Investigación. México: McGraw-Hill.

INEGI. (2004). Instituto Nacional de Estadística. México, DF: Geografía e Informática.

INEGI. (2009). Censos Económicos. México, DF: Instituto Nacional de Estadística y Geografía.

Janjuha-Jivraj, S., \& Spence, L. J. (2009). The nature of reciprocity in family firm succession. International Small Business Journal, 27(6), 702-719.

Jensen, M.C. (1994). Self interest, altruism, incentives, and agency theory. Journal of Applied Corporate Finance, summer 1994. https://ssrn.com/abstract $=5566$.

Kellermanns, F. W., Eddleston, K. A., \& Zellweger, T. M. (2012). Extending the socioemotional wealth perspective: A look at the dark side. Entrepreneurship Theory and Practice, 36(6), $1175-1182$.

Kidwell, L. A., \& Kidwell, R. E. (2010). Fraud in the family: How family firm characteristics can shape illegal behavior. Conference paper, August 2010. Conference: American Accounting Association Annual Meeting, at San Francisco, CA.

Lambrecht, J., \& Uhlaner, L. (2005). Responsible ownership of the family business: State-of-the-art. In FBN-IFERA World Academic Forum, Brussels, Belgium. CD-Rom.

Leana, C. R., \& Van Buren, H. J. (1999). Organizational social capital and employment practices. Academy of Management Review, 24(3), 538-555.

Lepoutre, J., \& Heene, A. (2006). Investigating the impact of firm size on small business social responsibility: A critical review. Journal of Business Ethics, 67(3), 257-273.

Long, R. G. (2011). Commentary: Social exchange in building, modeling, and managing family social capital. Entrepreneurship Theory and Practice. Special Issue: Theory of the Family Enterprise. 35 (6), 1229-1234.

Marques, P., Presas, P., \& Simon, A. (2014). The heterogeneity of family firms in CSR engagement the role of values. Family Business Review, 27(3), 206-227.

Mitchell, R., Agle, B., Chrisman, J., \& Spence, L. (2011). Toward a theory of stakeholder salience in family firms. Business Ethics Quarterly, 21(2), 235-255. 
Mizruchi, M. S. (1996). What do interlocks do? An analysis, critique, and assessment of research on interlocking directorates. Annual Review of Sociology, 22, 271-298.

Moran, P., \& Ghoshal, S. (1996). Value creation by firms. Academy of Management Proceedings, 1, 41-45.

Mustakallio, M., Autio, E., \& Zahra, S. A. (2002). Relational and contractual governance in family firms: Effects on strategic decision making. Family Business Review, 15(3), 205-222.

Nahapiet, J., \& Ghoshal, S. (1998). Social capital, intellectual capital, and the organizational advantage. Academy of Management Review, 23(2), 242-266.

Niehm, L. S., Swinney, J., \& Miller, N. J. (2008). Community social responsibility and its consequences for family business performance. Journal of Small Business Management, 46(3), 331-350.

O'Boyle, E. H., Rutherford, M. W., \& Pollack, J. M. (2010). Examining the relation between ethical focus and financial performance in family firms: An exploratory study. Family Business Review, 23(4), 310-326.

Perrini, F., \& Minoja, M. (2008). Strategizing corporate social responsibility: Evidence from an Italian medium-sized, family-owned company. Business Ethics: A European Review, 17(1), 47-63.

Preuss, L., \& Perschke, J. (2010). Slipstreaming the larger boats: Social responsibility in medium-sized businesses. Journal of Business Ethics, 92(4), 531-551.

Quazi, A. M., \& O'Brien, D. (2000). An empirical test of a crossnational model of corporate social responsibility. Journal of Business Ethics, 25, 33-51.

Reyes, F. J., \& Preiss, A. (2015). Strategic management: A survival need for Mexican SMEs. Business Management and Strategy, 6(1), 65-73.

Salvato, C., \& Melin, L. (2008). Creating value across generations in family-controlled businesses: The role of family social capital. Family Business Review, 21(3), 259-276.

Schulze, W. S., Lubatkin, L. H., Dino, R. N., \& Buchholtz, A. K. (2011). Agency relationships in family firms: Theory and evidence. Organizational Science, 12(2), 99-116.

Sharma, P., \& Sharma, S. (2011). Drivers of proactive environmental strategy in family firms. Business Ethics Quarterly, 21(02), 309-334.

Sirmon, D. G., \& Hitt, M. A. (2003). Managing resources: Linking unique resources, management, and wealth creation in family firms. Entrepreneurship Theory and Practice, 27(4), 339-358.

Sorenson, R. L., Goodpaster, K. E., Hedberg, P. R., \& Yu, A. (2009). The family point of view, family social capital, and firm performance: An exploratory test. Family Business Review, 22(3), 239-253.
Spence, L. J. (1999). Does size matter? The state of the art in small business ethics. Business Ethics: An European Review, 8(3), 163-174.

Spence, L. J. (2007). CSR and small business in a European policy context: The five "C" $\mathrm{s}$ of CSR and small business research agenda. Business and Society Review, 112(4), 533-552.

Tapies, J., \& Fernández Moya, M. (2012). Values and longevity in family business: Evidence from a cross-cultural analysis. Journal of Family Business Management, 2(2), 130-146.

Tsai, W., \& Goshal, S. (1998). Social capital and value creation: The role of intrafirm networks. The Academy of Management Journal, 41(4), 464-476.

Uhlaner, L. M., Kellermanns, F. W., Eddleston, K. A., \& Hoy, F. (2012). The entrepreneuring family: A new paradigm for family business research. Small Business Economics, 38(1), 1-11.

Uhlaner, L. M., van Goor-Balk, H. J. M., \& Masurel, E. (2004). Family business and corporate social responsibility in a sample of Dutch firms. Journal of Small Business and Enterprise Development, 11, 186-194.

Wade-Benzoni, K. (2002). A golden rule over time: Reciprocity in intergenerational allocation decisions. Academy of Management Journal, 45, 1011-1030.

Watkins-Fassler, K., Fernandez-Perez, V., \& Rodríguez-Ariza, L. (2017). President interlocking, family firms and performance during turbulent times: Evidence from Latin America. European Journal of Family Business, 6, 63-74.

Won, Y. O., Young, K. C., \& Martynov, A. (2011). The effect of ownership structure on corporate social responsibility: Empirical evidence from Korea. Journal of Business Ethics, 104, 283-297.

Wright, P. M., Dunford, B. B., \& Snell, S. A. (2001). Human resources and the resource based view of the firm. Journal of Management, 27(6), 701-721.

Yeung, H. W., \& Soh, T. M. (2000). Corporate governance and the global reach of Chinese family firms in Singapore. Seoul Journal of Economics, 13, 301-335.

Yin, R.K. (1989). Case study research: Design and methods, revised edition. Applied Social Research Methods Series, 5.

Yin, R. K. (2003). Case study research (4th ed.). New York: Sage.

Zellweger, T. M., Nason, R. S., Nordqvist, M., \& Brush, C. G. (2013). Why do family firms strive for nonfinancial goals? An organizational identity perspective. Entrepreneurship Theory and Practice, $37(2), 229-248$

Zikmund, W. G. (2003). Sample designs and sampling procedures. Business Research Methods, 7, 368-400. 